\title{
QUALIDADE PÓS-COLHEITA DE DIFERENTES HÍBRIDOS DE MELÃO-AMARELO ARMAZENADOS SOB REFRIGERAÇÃO ${ }^{1}$
}

\author{
HALAN VIEIRA DE QUEIROZ TOMAZ², EDNA MARIA MENDES AROUCHA 3 , \\ GLAUBER HENRIQUE DE SOUSA NUNES ${ }^{4}$, FRANCISCO BEZERRA NETO ${ }^{4}$, \\ HALEN VIEIRA DE QUEIROZ TOMAZ ${ }^{5}$, RONIALISON FERNANDES QUEIROZ ${ }^{5}$
}

RESUMO-Este trabalho teve por objetivo avaliar a vida útil de cinco híbridos de melão cv. amarelo (AF-7100, AF-1498, AF-5107, AF-4945 e AF-1805) produzidos no Agropolo Assu-Mossoró-RN. Após atingido o estádio de maturação, os frutos foram colhidos e conduzidos ao Laboratório de Pós-Colheita da Universidade Federal Rural do Semiárido (UFERSA), onde se retiraram ao acaso 12 frutos de cada híbrido para caracterização no tempo zero. Em seguida, os demais frutos foram pesados, identificados e armazenados em câmara refrigerada regulada a $10 \pm 1^{\circ} \mathrm{C}$ e $90 \pm 2 \%$ UR, onde permaneceram por $7 ; 14 ; 21 ; 28$; 35 ; 42; 49; 56; 63 e 70 dias. Em cada intervalo de tempo, avaliaram-se nos frutos: perda de massa, firmeza da polpa, aparência externa e interna, pH, acidez titulável, sólidos solúveis, açúcares redutores e açúcares solúveis totais. O delineamento experimental foi o inteiramente casualizado, em esquema de parcelas subdivididas no tempo. Na parcela, está o fator híbridos e, na subparcela, os tempos de armazenamento. Foram utilizadas três repetições, sendo a parcela constituída por três frutos. Houve interação significativa entre híbrido e período de armazenamento para a firmeza de polpa dos frutos. Para as demais características avaliadas, foi observado o efeito dos fatores principais. Durante o período de conservação, o híbrido AF-7100 apresentou maior firmeza dos frutos, seguida da cultivar AF-5107. Houve aumento na perda de massa durante 0 armazenamento e não se observaram danos nas aparências externas e internas até 42 e 28 dias de armazenamento, respectivamente. Termos para Indexação: Cucumis melo L., vida útil, avaliação de cultivares.

\section{POSTHARVEST QUALITY OF DIFFERENT YELLOW MELON HYBRIDS STORED UNDER REFRIGERATION}

ABSTRACT - The objective of this work was to evaluate the shelf life of five yellow melon hybrids (AF7100, AF-1498, AF-5107, AF-4945 e AF-1805) grown in the Agropole Mossoró-Assu, RN. Fruits were harvested at commercial maturity and transported to the Postharvest Laboratory of the Universidade Federal Rural do Semi-Árido (UFERSA). Upon arrival, twelve fruits were randomly selected of each hybrid for characterization at zero time of storage. Right after, the other fruits were weighed, identified and stored in cold room at $10 \pm 1^{\circ} \mathrm{C}$ and $90 \pm 2 \% \mathrm{RH}$ for $7,14,21,28,35,42,49,56,63$ and 70 days. For all these storage times, it was performed evaluations for loss of mass, pulp firmness, external and internal appearances, $\mathrm{pH}$, titratable acidity, soluble solids content, reducing sugars, and total soluble sugars. The experimental design was completely randomized in subdivided parcels according to the time. The parcel has the cultivar and the subparcel has the storage periods. It was used three replications, and the parcel was constituted by three fruits. There was a significant interaction between cultivars and storage time on the pulp firmness of the fruits. It was observed significant effects of the main factors on the other assessed traits. Higher fruit pulp firmness was observed in the hybrid AF-7100, followed by the hybrid AF-5107. There was an increment in the percentage of mass loss during the storage. It was not observed any damage on the external and internal appearances until 42 and 28 days of storage, respectively.

Index terms: Cucumis melo L., shelf life, cultivars evaluation.

${ }^{1}$ (Trabalho 223-08). Recebido em: 29-08-2008. Aceito para publicação em: 27-10-2009.

${ }^{2}$ Mestrando em Fitotecnia, ESALQ/USP, Departamento de Produção Vegetal - Setor Agricultura. Av. Pádua Dias, 11. Cx. Postal 9, CEP: 13418-900. Piracicaba-SP, Brasil. E-mail: halanvieira@gmail.com ;Autor para correspondência.

${ }^{3}$ Prof. Adjunto I, Departamento de Agrotecnologia e Ciências Sociais, Universidade Federal Rural do Semiárido (UFERSA), BR 110, Km 47, 59625-900, Mossoró-RN, Brasil. E-mail: aroucha@ufersa.edu.br

${ }^{4}$ Programa de Pós-Graduação em Fitotecnia, UFERSA, Mossoró-RN, Brasil. E-mail: glauber@ufersa.edu.br; bezerra@ufersa.edu.br ${ }^{5}$ Mestrando em Fiototecnia, UFERSA, Mossoró-RN, Brasil. E-mail: halenkvieira@hotmail.com; ronialison@hotmail.com 


\section{INTRODUÇÃO}

O melão é uma cucurbitácea cultivada em várias regiões do mundo e tem grande expressão econômica. Em 2007, a exportação de melão atingiu a cifra de 128 milhões de dólares, com um volume de 204,5 toneladas, representando um aumento de 45,3\% em relação ao ano de 2006, sendo a segunda fruta brasileira mais exportada em 2007 (SECEX, 2008).

O Brasil é um dos três maiores produtores mundiais de frutas. Em 2006, produziu cerca de 42 milhões de toneladas em um elenco de 20 espécies, com área de 2,2 milhões de hectares (IBGE, 2008). De acordo com o Instituto Brasileiro de Frutas (IBRAF), o incremento de produção tem-se mantido na média de 4,5\% ao ano. Essa mesma instituição estimou uma produção de 43,7 milhões de toneladas de frutas no ano de 2007. Não obstante esses valores, o Brasil exporta pouco mais de $2 \%$ da sua produção de frutas in natura, ocupando o $15^{\circ}$ lugar entre os países exportadores, segundo dados do Brasil (2008).

Os principais estados produtores encontramse na região Nordeste, com destaque para o Rio Grande do Norte e o Ceará, responsáveis por mais de $80 \%$ da produção nacional. As boas condições climáticas, aliadas à alta tecnologia de produção empregadas pelas empresas produtoras, têm contribuído para o sucesso dos referidos estados (NUNES et al., 2005).

Especificamente no Agropolo Mossoró-Assu, a quase totalidade das cultivares são híbridos simples obtidos do cruzamento de linhagens endogâmicas. Exceções são as variedades de polinização aberta de melão do tipo Honey Dew, comumente chamado de “Orange Flesh” pelos produtores. O melão do tipo amarelo ainda é o preferido, totalizando mais de $70 \%$ da área plantada. Esse tipo de melão pertence à variedade botância Inodorus Naud., tendo como principais características a ausência de aroma, casca espessa e firme, conferindo aos frutos considerável resistência à pressão e à perda de água e elevada conservação pós-colheita (AGROV, 2008).

Um híbrido desejado é aquele produtivo ( $\geq$ $25 \mathrm{t} \mathrm{ha}^{-1}$ ) e com excelentes qualidades de fruto, como alto teor de sólidos solúveis ( $\geq 10 \%$ ) e valor mínimo de firmeza da polpa ( $\geq 22 \mathrm{~N}$ ). Em adição, em razão da distância entre os mercados consumidores do melão nacional, Europa e Estados Unidos, exige-se que os frutos tenham maior vida pós-colheita, em torno de 30 dias. As características relacionadas à vida pós-colheita de frutos de meloeiro são as aparências externa e interna do fruto, bem como a perda de peso do mesmo (GOMES JÚNIOR et al., 2001).
Devido à dinâmica dos programas de melhoramento do meloeiro, principalmente em empresas privadas, a cada ano são produzidas dezenas de cultivares. A adoção de qualquer um desses híbridos sem uma prévia avaliação da qualidade e a vida útil pós-colheita podem comprometer o comércio com o mercado externo, uma vez que o consumidor europeu é extremamente exigente na qualidade das frutas consumidas (NUNES et al., 2005). Todavia, esses genótipos, em muitas situações, não são avaliados pelas próprias empresas produtoras, seguindo os princípios básicos da experimentação agrícola. Com efeito, a avaliação com critérios científicos é de suma importância para a recomendação mais segura das cultivares.

No tocante à qualidade e vida útil pós-colheita, em razão do exigente consumidor, é fundamental que o híbrido cultivado possa chegar ao mercado europeu com excelente qualidade para consumo em poucos dias. Em muitas situações, as avaliações para os referidos aspectos são negligenciadas, acarretando problemas futuros na comercialização, pois mesmo com bom desempenho produtivo no campo, a qualidade do fruto pode ser inferior. Assim sendo, é imprescindível que avaliações de qualidade e póscolheita sejam realizadas para assegurar a recomendação das cultivares mais promissoras.

Diante dessas considerações, o objetivo do presente trabalho foi avaliar a qualidade e a vida útil pós-colheita de cinco híbridos de melão-amarelo.

\section{MATERIAL E MÉTODOS}

Foram utilizados cinco híbridos de melão cv. amarelo (AF-7100, AF-1498, AF-5107, AF-4945 e AF-1805) produzidos no Agropolo Assu-MossoróRN. O cultivo foi realizado em outubro de 2006, em uma Fazenda Comercial no município de Mossoró$\mathrm{RN}$, localizada a uma latitude sul de $5^{\circ} 11^{\text {' e uma }}$ longitude oeste de $37^{\circ} 20^{\prime}$, e altitude de $18 \mathrm{~m}$. O clima da região, de acordo com a classificação de Köeppen, é do tipo BSwh', ou seja , quente e seco; com precipitação pluviométrica bastante irregular, média anual de $673,9 \mathrm{~mm}$; temperatura de $27^{\circ} \mathrm{C}$ e umidade relativa do ar média de 68,9\% (CARMO FILHO \& OLIVEIRA, 1995).

O plantio do melão foi realizado através de mudas obtidas em bandejas de isopor com 200 células $\mathrm{O}$ espaçamento foi de 2,0 x 0,4 m, com uma muda por cova, resultando numa população de 12.500 plantas ha $^{-1}$. O delineamento no campo foi o inteiramente casualizado, pois trata-se de uma área pequena e bastante homogênea quanto às propriedades físicas e químicas do solo, sempre 
utilizada para experimentos.

Ao atingirem a maturidade fisiológica, tamanho, peso e coloração da casca, característicos da cultivar, os melões foram colhidos e transportados para o Laboratório de Pós-Colheita da UFERSA, onde foram caracterizados previamente através da amostragem de 12 frutos de cada híbrido. Após a limpeza, pesagem e identificação dos melões, estes foram armazenados por 70 dias, sendo avaliados em intervalos de 7 dias. Foi utilizada uma câmara de refrigeração regulada a $10 \pm 1^{\circ} \mathrm{C}$ e $90 \pm 2 \%$ UR. O delineamento experimental foi o inteiramente casualizado, em esquema de parcelas subdivididas no tempo. Na parcela, considerou-se o fator híbridos e, na subparcela, os tempos de armazenamento. Foram utilizadas três repetições, sendo a unidade experimental constituída por três frutos.

A cada intervalo de tempo, nove frutos de cada híbrido foram avaliados quanto à perda de massa (PM), determinada pela diferença entre a massa no tempo inicial e aquela obtida em cada época, sendo expressa em porcentagem (\%). Para a firmeza da polpa (FP), os frutos foram divididos longitudinalmente em duas partes e, em cada uma delas, foram determinadas duas leituras na polpa, em locais opostos na região equatorial, com um penetrômetro da marca McCormick, modelo FT 327 analógico (ponteira de $8 \mathrm{~mm}$ de diâmetro), os resultados foram expressos em $\mathrm{N}$.

Na avaliação da aparência externa e interna (AE e AI), adotou-se uma escala visual e subjetiva, atribuída por três pessoas treinadas. A escala corresponde a notas variando de 1 a 5 , de acordo com a severidade dos defeitos na área externa (depressões, murcha, lesões fúngicas ou injúria pelo frio) e interna (colapso interno, sementes soltas e/ou líquido na cavidade das sementes) do fruto. Dessa forma: $1=$ defeito extremamente severo (acima de 50\% do fruto afetado); $2=$ defeito severo (31 - 50\%); $3=$ defeito moderado (11 - 30\%); $4=$ defeito leve $(1-10 \%)$ e $5=$ ausência de defeito, sempre utilizando as mesmas pessoas nas avaliações e, posteriormente, obtendo-se a média das notas (Wang et al., 1996). Frutos com nota inferior a 3 foram considerados inadequados para comercialização;

Para acidez titulável (AT), seguiu-se a metodologia do Instituto Adolfo Lutz (1985), determinada por titulação de uma alíquota de $10 \mathrm{~mL}$ de suco, em duplicata, à qual foram adicionados $40 \mathrm{~mL}$ de água destilada e três gotas do indicador fenolftaleína alcoólica a 1\%, em seguida, procedeu a titulação com solução de $\mathrm{NaOH}$ a $0,1 \mathrm{~N}$, os resultados expressos em porcentagem de ácido cítrico. O potencial hidrogeniônico $(\mathrm{pH})$ foi determinado no suco em duplicata, utilizando-se de um potenciômetro digital da marca Marte, modelo MB-10 (AOAC, 1992);

A determinação dos sólidos solúveis (SS) foi realizada utilizando o refratômetro digital modelo PR-100 Palette (Attago Co. Ltd., Japan), com correção automática de temperatura e leitura na faixa de 0 a $32{ }^{\circ}$ Brix (AOAC, 1992). Para os açúcares redutores (AR), adotou-se o método do ácido dinitrosalicílico (DNS) e, para os açúcares solúveis totais (AST), foram analisados segundo metodologia de Yemn \& Willis (1954).

Inicialmente, os dados foram submetidos à análise de variância. Os níveis do fator qualitativo (Híbrido) foram comparados pelo teste de Tukey, enquanto para o fator quantitativo (Tempo), procedeu-se o ajustamento de modelos de regressão. A escolha dos modelos seguiu os critérios de significância do modelo e dos parâmetros do modelo, significância do desvio de regressão e estimativa do coeficiente de determinação $\left(\mathrm{R}^{2}\right)$. Utilizou-se o teste F para verificar a significância do modelo e do desvio de regressão. Para o teste dos parâmetros, foi utilizado o teste t de Student. Em todas as análises, foi adotado o nível nominal de significância de 5\% de probabilidade. Foram utilizados os programas SAEG e Table Curve (Jandel Scientific, 1991) para o processamento das análises.

\section{RESULTADOS E DISCUSSÃO}

Houve interação significativa entre os fatores estudados, híbrido e tempo de armazenamento, somente para firmeza da polpa (Figura 1). Para as demais características, foram detectados efeitos isolados de híbridos e/ou tempo de armazenamento (Tabela 1 e Figuras 2, 3, 4 e 5).

Com relação à firmeza da polpa, a interação significativa evidencia resposta diferencial dos híbridos em função dos tempos de armazenamento. Esse fato é evidenciado na Figura 1, pelas diferenças nas magnitudes da firmeza da polpa ao longo do armazenamento. O teste de identidade de modelos significativo indica que o comportamento dos híbridos foi diferente, em especial devido às estimativas dos interceptos das equações, uma vez que a redução da firmeza, em função da variação no tempo de armazenamento (coeficientes de regressão), foi muito próxima, indicando homogeneidade.

A firmeza da polpa é um atributo de qualidade importante, em razão de os frutos com maior firmeza serem mais resistentes às injúrias mecânicas durante o transporte e a comercialização. Frutos colhidos com maior firmeza da polpa têm, geralmente, maior conservação e vida útil pós-colheita. Em estudos 
realizados com vários tipos de melão no Agropolo Mossoró-Assu, Filgueiras et al. (2000) observaram o valor mínimo de $22 \mathrm{~N}$ para firmeza da polpa no momento da colheita. No presente trabalho, todos os híbridos têm firmeza da polpa acima do valor mínimo. Por outro lado, a firmeza da polpa diminuiu linearmente com o tempo de armazenamento, fato comumente observado em trabalhos de pós-colheita no meloeiro (MICCOLIS \& SALTVEIT JUNIOR, 1991; MENEZES et al., 2001; MENDONÇA et al., 2004 ). Os híbridos AF-7100 e AF-5107 destacaram-se por manterem-se mais firmes durante maior período de armazenamento. Trinta e cinco dias após a colheita, esses dois híbridos possuíam frutos com excelentes estimativas de firmeza da polpa (Figura 1).

A diminuição da firmeza foi detectada, também, em cultivares de melão inodorus por Miccolis \& Saltveit Jr. (1991), Menezes et al. (2001) e Mendonça et al. (2004) durante o armazenamento.

Durante o período de armazenamento, uma característica importante a ser analisada é a perda de massa, ocasionada pela transpiração dos frutos. A perda de massa pode acarretar sérios efeitos sobre as propriedades físicas, nutricionais, fisiológicas, patológicas e de aparência do produto. Em adição, do ponto de vista econômico, a perda de massa é uma característica fundamental, pois a venda dos frutos é feita em unidade de massa.

Os híbridos não diferiram entre si quanto à perda de massa (Tabela 1). Observou-se incremento da perda de peso ao longo do período de armazenamento (Figura 2), fato observado por Menezes et al. (2001), trabalhando com o híbrido amarelo TSX 32096 em temperatura ambiente $\left(30 \pm 1^{\circ} \mathrm{C}\right.$ e $50 \pm 5 \%$ UR) por 25 dias, bem como por Mendonça et al. (2004) com o híbrido RX 20094 em condições semelhantes por 42 dias. Comparando-se com cada um dos trabalhos citados, a média da perda de massa dos híbridos do presente trabalho foi inferior. Todavia, os frutos foram armazenados em condições de refrigeração controlada $\left(10 \pm 1^{\circ} \mathrm{C}\right.$ e $\left.90 \pm 2 \%\right)$. Ressaltase que, no caso de melão-amarelo, temperaturas inferiores a $8,0^{\circ} \mathrm{C}$ podem causar injúrias pelo frio (GOMES JÚNIOR, 2000).

As aparências externa e interna são características fundamentais na comercialização, uma vez que a aparência do fruto é o primeiro atributo que chama a atenção do consumidor. Frutos sem boa aparência não são comercializados no mercado externo, servindo apenas para o mercado nacional. Os híbridos diferiram entre si para aparência externa, mas não diferiram para a aparência interna (Tabela 1). Apesar da diferença do ponto de vista estatístico da aparência externa, do ponto de vista pragmático, todos os híbridos estão em condições excelentes para comercialização, pois a média está muito próxima da nota máxima $(5,0)$.

Além disso, apesar de uma pequena redução com o tempo de armazenamento da aparência externa e de uma redução maior da aparência externa (Figura 3), os valores observados ao final do tempo de avaliação ainda indicam frutos comercializáveis, pois frutos com nota igual ou superior a 3,0 são considerados como adequados para o consumo (GOMES JUNIOR et al., 2001).

Resultados semelhantes foram encontrados por Menezes et al. (2001) para aparência externa e interna, onde os genótipos estudados apresentaram nota média 4,0 aos 42 dias de armazenamento em temperatura ambiente.

A acidez dos frutos diminuiu e, paralelamente, houve acréscimo no pH durante o período de armazenamento dos frutos (Figura 4). Para a acidez, apenas o híbrido AF-7100 foi inferior aos demais, e em relação ao pH, os híbridos AF-7100 e AF-5107 foram superiores. Para Menezes et al. (1998), a variação nos teores de acidez durante o armazenamento do melão têm pouco significado prático em função da baixa concentração de ácido cítrico encontrado, teores que não dão para causar sensiblidade prática para quem os consome.

Observou-se efeito de híbridos para o teor de sólidos solúveis, com destaque para o híbrido AF5107 com maior média, seguido dos híbridos AF-1498 e AF-4945. Segundo Filgueiras et al. (2000), frutos do tipo amarelo, destinados ao mercado externo, devem ser colhidos com valores entre 10 e $12 \%$. Com efeito, conforme esse autor, apenas o híbrido AF-5107 estaria apto para comercialização externa. Todavia, híbridos de melão-amarelo têm sido comercializados com o mercado europeu com valores abaixo de 10\% (SALES JÚNIOR et al., 2006).

Não foi observada alteração significativa nos teores de sólidos solúveis ao longo do tempo de armazenamento. Constataram-se pequenas variações no teor de sólidos solúveis, sendo a diferença entre o valor máximo e mínimo de apenas 1\%. Resultados semelhantes foram verificados por Carvalho et al. (1995) em melão-amarelo "Yellow King” armazenado em temperatura ambiente.

Houve diferença quanto ao teor de açúcares redutores e açúcares solúveis totais de acordo com o híbrido (Tabela 2). Verificou-se que os híbridos AF-7100 e AF-5107 apresentaram teores de açúcares redutores semelhantes e superiores aos demais híbridos estudados. Enquanto para os teores de AST, os híbridos AF-7100 e AF-1805 apresentaram teores 
inferiores aos demais (8,21-8,71\%). Esses resultados foram semelhantes aos encontrados em melão-amarelo por Menezes et al. (2001), em que a quantidade de açúcares solúveis totais para os genótipos TSX 32096 e SUNEX 7057 foram em média de 8,2\% e 8,8\%, respectivamente. Zhang \& $\mathrm{Li}$ (2005) enfatizaram que o melão possui em torno de $97 \%$ dos sólidos solúveis constituídos por açúcares solúveis, de forma que a sacarose compreende cerca de 50\% desse total.
Os teores de AR e AST diminuíram durante o armazenamento dos frutos, com uma média, no início do experimento (0 dia), de 5,87\% e 7,02\% e, ao final (70 dias), de 3,03\% e 6,09\%, respectivamente (Figura 5), verificando-se uma perda respectiva de 48,38\% e 13,24\% durante o tempo transcorrido. Menezes et al. (2001) detectaram também em melão-amarelo redução nos açúcares redutores para o genótipo TSX 32096 de 5,34\% para 3,21\%, do início ao final do experimento, representando uma perda em torno de $39,88 \%$.

TABELA 1 - Perda de massa (PM), aparência externa (AE) e interna (AI), pH, acidez titulável (AT), solúveis sólidos (SS), açúcares redutores (AR) e açúcares solúveis totais (AST) em função dos híbridos

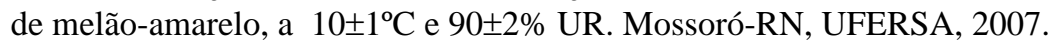

\begin{tabular}{ccccccccc}
\hline \multirow{2}{*}{ Híbrido } & \multicolumn{7}{c}{ Características avaliadas } \\
\cline { 2 - 9 } & PM $^{1}$ & AE & AI & pH & AT $^{2}$ & SS $^{3}$ & AR $^{1}$ & AST $^{1}$ \\
\hline AF-7100 & $2,09 \mathrm{a}^{*}$ & $4,90 \mathrm{ab}$ & $4,85 \mathrm{a}$ & $6,05 \mathrm{a}$ & $0,117 \mathrm{~b}$ & $8,58 \mathrm{c}$ & $5,30 \mathrm{a}$ & $7,37 \mathrm{~b}$ \\
$\mathrm{AF}-1498$ & $2,15 \mathrm{a}$ & $4,98 \mathrm{a}$ & $4,85 \mathrm{a}$ & $5,93 \mathrm{~b}$ & $0,144 \mathrm{a}$ & $9,52 \mathrm{~b}$ & $4,20 \mathrm{~b}$ & $8,31 \mathrm{a}$ \\
$\mathrm{AF}-5107$ & $2,06 \mathrm{a}$ & $4,90 \mathrm{ab}$ & $4,76 \mathrm{a}$ & $6,12 \mathrm{a}$ & $0,137 \mathrm{a}$ & $10,04 \mathrm{a}$ & $5,30 \mathrm{a}$ & $8,71 \mathrm{a}$ \\
$\mathrm{AF}-4945$ & $2,23 \mathrm{a}$ & $4,88 \mathrm{ab}$ & $4,71 \mathrm{a}$ & $5,93 \mathrm{~b}$ & $0,138 \mathrm{a}$ & $9,38 \mathrm{~b}$ & $3,87 \mathrm{~b}$ & $8,21 \mathrm{a}$ \\
$\mathrm{AF}-1805$ & $2,11 \mathrm{a}$ & $4,82 \mathrm{~b}$ & $4,67 \mathrm{a}$ & $5,89 \mathrm{~b}$ & $0,143 \mathrm{a}$ & $8,68 \mathrm{c}$ & $3,99 \mathrm{~b}$ & $7,40 \mathrm{~b}$ \\
\hline
\end{tabular}

*Médias seguidas de mesma letra na coluna não diferem entre si, pelo teste Tukey, ao nível de 5 \% de probabilidade.

${ }^{1}(\%) ;{ }^{2}$ (\% ácido cítrico); ${ }^{3} \mathrm{Brix}$

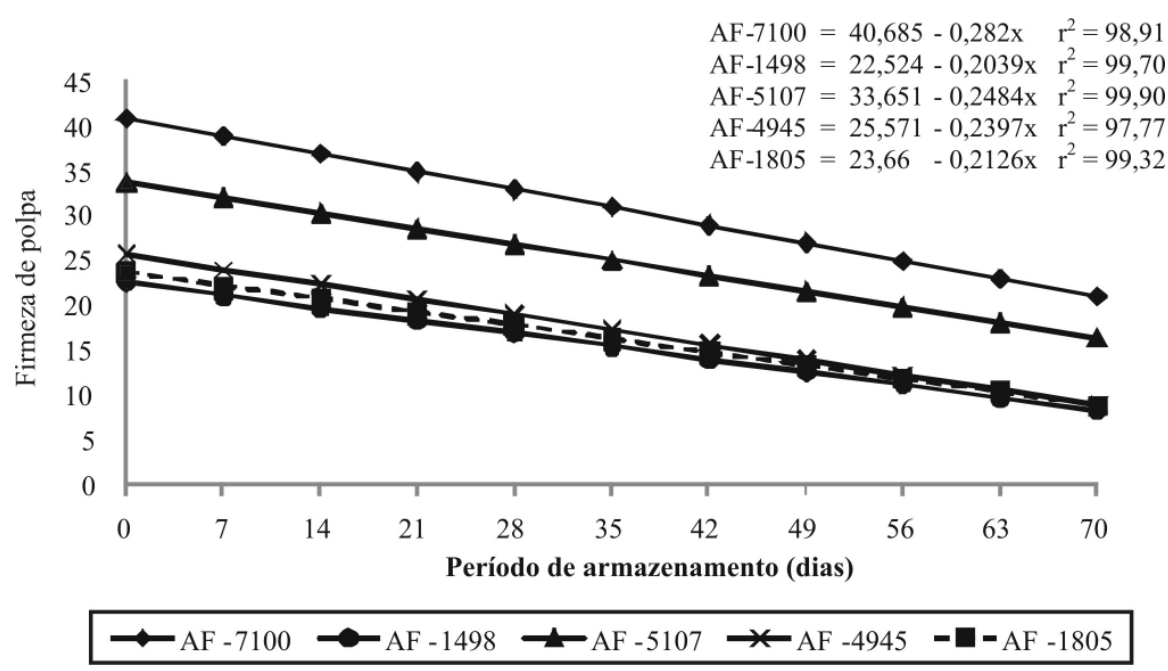

FIGURA 1 - Firmeza da polpa dos híbridos de melão-amarelo em função do período de armazenamento dos frutos a $10 \pm 1^{\circ} \mathrm{C}$ e $90 \pm 2 \%$ UR. Mossoró-RN, UFERSA, 2007. 


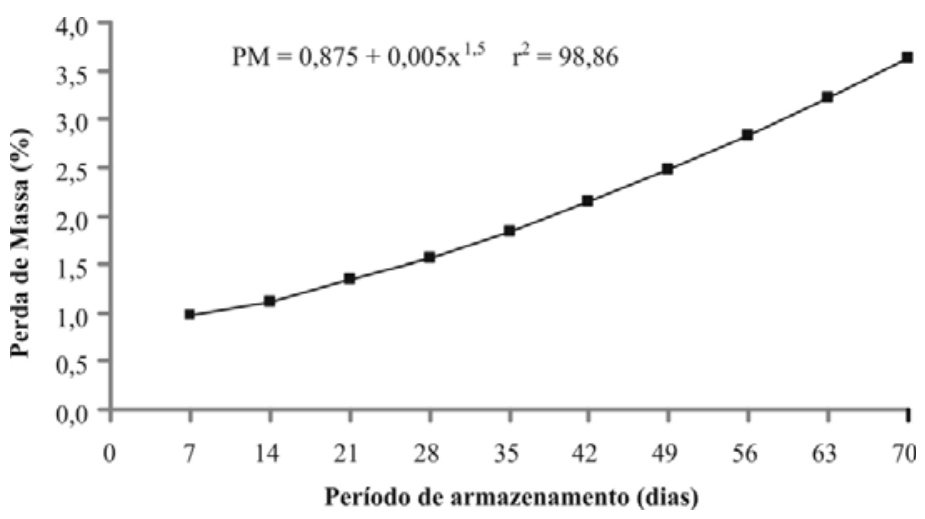

FIGURA 2 - Perda de massa dos híbridos de melão-amarelo em função do período de armazenamento dos frutos a $10 \pm 1^{\circ} \mathrm{C}$ e $90 \pm 2 \%$ UR. Mossoró-RN, UFERSA, 2007.

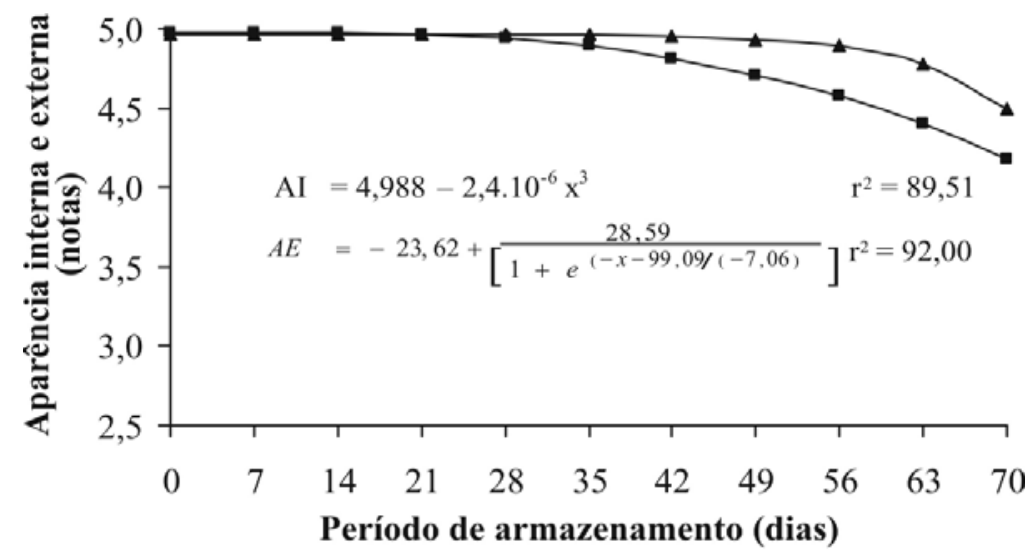

$\mathrm{AI} \rightarrow \mathrm{AE}$

FIGURA 3 - Aparência interna (AI) e externa (AE) dos híbridos de melão-amarelo em função do período de armazenamento dos frutos a $10 \pm-1^{\circ} \mathrm{C}$ e 90+2\% UR. Mossoró-RN, UFERSA, 2007.

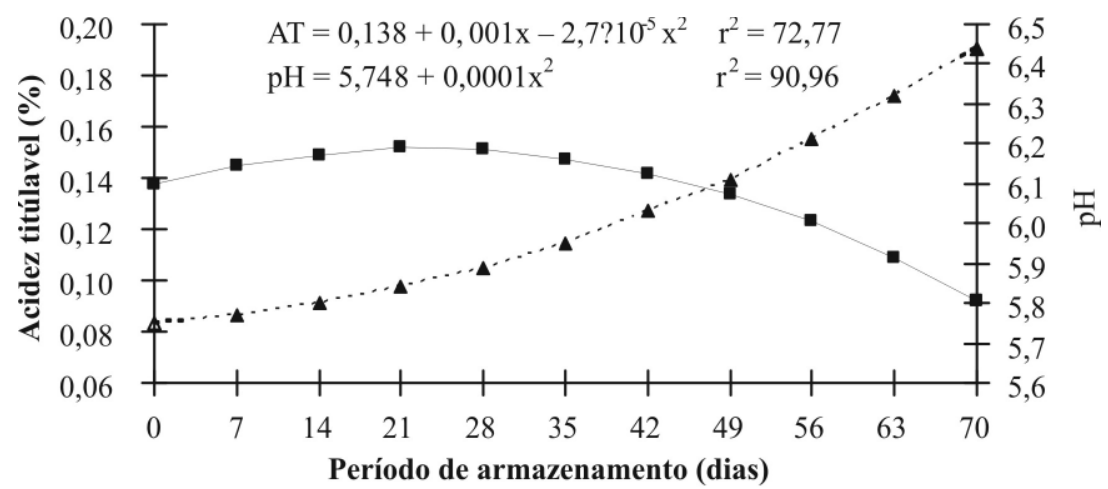

Acidez $\cdots \Delta \cdot \cdots \mathrm{pH}$

FIGURA 4 - Acidez titulável e pH dos híbridos de melão-amarelo em função do período de armazenamento dos frutos a $10 \pm 1^{\circ} \mathrm{C}$ e $90 \pm 2 \%$ UR. Mossoró-RN, UFERSA, 2007. 


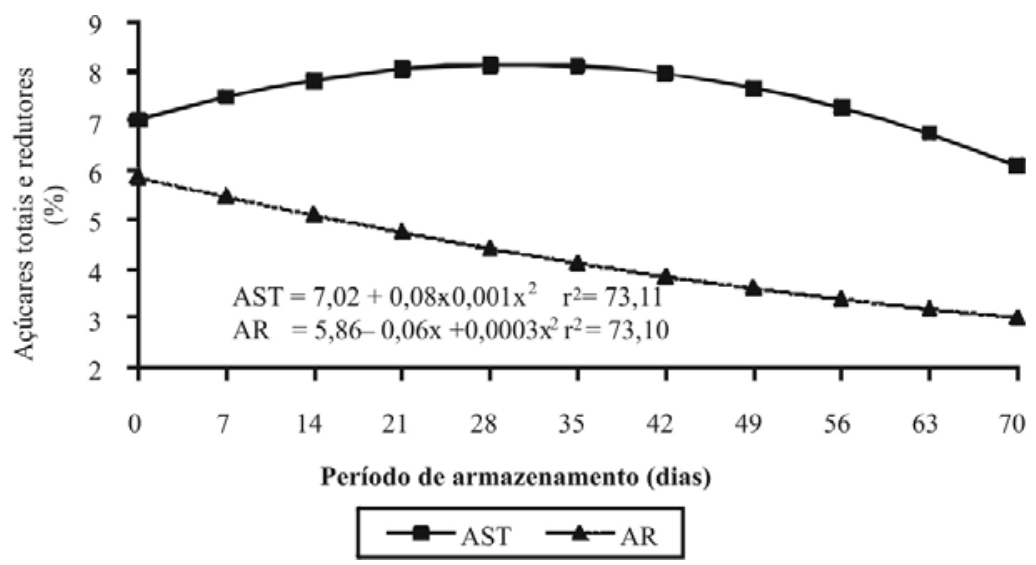

FIGURA 5 - Açúcares solúveis totais (AST), açúcares redutores (AR) dos híbridos de melão-amarelo em função do período de armazenamento dos frutos a $10 \pm 1^{\circ} \mathrm{C}$ e $90 \pm 2 \%$ UR. Mossoró-RN, UFERSA, 2007.

\section{CONCLUSÕES}

Dentro do contexto da vida útil pós-colheita, todos os híbridos avaliados possuíram elevada vida útil em razão das excelentes notas para as aparências externa e interna $(\cong 5,0)$ mesmo após todo o período de armazenamento e reduzida perda de massa aos 35 dias. Não obstante, o híbrido AF-5107 sobressaiu-se por manter a boa qualidade dos seus frutos em razão, principalmente, de sua elevada firmeza da polpa ao longo do tempo de armazenamento e maior valor do teor de sólidos solúveis (10,04\%).

\section{AGRADECIMENTOS}

Ao Conselho Nacional de Desenvolvimento Científico e Tecnológico (CNPq), pela concessão da bolsa de Iniciação Científica (PIBIC/UFERSA) ao primeiro autor.

\section{REFERÊNCIAS}

AGROV 2008. Disponível em: <http://www.agrov. com>. Acesso em: 20 mar. 2008.

AOAC - ASSOCIAÇÃO OF OFFICIAL ANALITICAL CHEMISTRY. Official methods analysis the Association of Official Analytical Chemistry. 12. ed. Arlington, 1992.

BRASIL. Ministério da Agricultura. Disponível em: <http://www.agricultura.gov.br/>. Acesso em: 05 fev. 2008.
CARMO FILHO, F. do; OLIVEIRA, O. F. de. Mossoró: um município do semiárido nordestino, caracterização climática e aspecto florístico. Mossoró: ESAM, 1995. 62p. (Coleção Mossoroense, série $B)$.

CARVALHO, M.I.F.; CHITARRA, M.I.F.; CHITARRA, A.B.; MENEZES, J.B. Vida útil pós-colheita de melão Yellow King. Revista Brasileira de Fruticultura, Jaboticabal, v.17, n.3, p.111-118, 1995.

FILGUEIRAS, H.A.C.; MENEZES, J.B.; ALVES, R.E.; COSTA, F.V.; PEREIRA, L.S.E.; GOMES JUNIOR, J. Colheita e manuseio pós-colheita. In: ALVES, R.E. (Org.). Melão Pós-colheita. Fortaleza: Embrapa Agroindústria Tropical, 2000. p. 23-43

GOMES JÚNIOR, J.; ARAUJO NETO, S.E.; MENEZES, J.B.; SIMÕES, A.N.; SILVA, G.G. Caracterização pós-colheita de melão "Piel de Sapo", genótipo Imara, sob condições ambientes. Revista Brasileira de Fruticultura, Jaboticabal, v.22, n. 1. p. 32-36. 2001.

GOMES JÚNIOR, J. Suscetibilidade a danos pelo frio de melões-amarelos 'AF-646' e 'Rochedo'. 2000. 42 f. (Dissertação de Mestrado) - Escola Superior de Agricultura de Mossoró, Mossoró, 2000.

INSTITUTO ADOLFO LUTZ. Normas analíticas, métodos químicos e físicos para análise de alimentos. 3. ed. São Paulo, 1985. v. 1, 533 p. 
IBGE. Produção agrícola municipal. Disponível em: <http://www.ibge.gov.br/servidor_arquivos_ est/>. Acesso em: 23 maio 2008.

JANDEL SCIENTIFIC. Table Curve: curve fitting software. Corte Madera, CA, 1991. 280p.

MENDONÇA, F.V.S.; MENEZES, J.B.; GUIMARÃES, A.A.; SIMÕES, A. do N.; SOUZA, G.L.F.M. Armazenamento do melão-amarelo, híbrido RX20094, sob temperatura ambiente. Horticultura Brasileira, Brasília, v.22, n.1, p.76-79, 2004.

MENEZES, J.B.; CHITARRA, A.B.; CHITARRA, M.I.F.; BICALHO, U.O. Caracterização do melão tipo Gália durante a maturação. Horticultura Brasileira, Brasília, v.16, n.2, p.123-127, 1998.

MENEZES, J.B.; GOMES JUNIOR, J.; ARAÚJO NETO, S.E.; SIMÕES, A.N. Armazenamento de dois genótipos de melão-amarelo sob condições ambiente. Horticultura Brasileira, Brasília, v.19, n.1, p.42-49, 2001.

MICCOLIS, V.; SALTVEIT Jr.; M.E. Morphological and physiological changes during fruit growth and maturation of seven melon cultivars. Journal of the American Society for Horticultural Science, Alexandria, v.116, n.5, p.1025-1029, 1991.

NUNES, G.H.S.; SANTOS JÚNIOR, J.J.; ANDRADE, F.V.; BEZERRANETO, F.; MENEZES, J.B.; PEREIRA, E.W.L. Desempenho de híbridos do grupo inodorus em Mossoró. Horticultura Brasileira, Brasília , v. 23, n. 1., p. 90-94, 2005.
SALES JÚNIOR, R.; DANTAS, F.; SALVIANO, A.M.; NUNES, G.H.S. Aspectos qualitativos do melão exportado pelo porto de Natal-RN. Ciência Rural, Santa Maria, v.36, n. 2, p. 286-289, 2006.

SECEX/MDIC. Secretaria de comércio exterior/ Ministério do Desenvolvimento Indústria e Comércio. Exportações brasileira de frutas. Disponível em: $<$ http://www2.desenvolvimento.gov.br/sitio/secex>. Acesso em: 11 jun. 2008.

WANG, Y.; WYLLIE, S.G.; LEACH, D.N. Chemical change during the development and ripening of the fruit of Cucumis melo L. cv. Makdimon. Journal of Agricultural and Food Chemistry, Easton, v.44, p.210-216, 1996.

YEMN, E.W.; WILLIS, A.J. The estimation of carbohydrate in plant extracts by anthrone. The Biochemical Journal, Colchester, v.57, n.3, p.508514, 1954.

ZHANG, M.F.; LI, Z.L. A comparison of sugaraccumulating patterns and relative compositions in developing fruits of two oriental melon varieties as determined by HPLC. Food Chemistry, Netherlands, v.90, p.785-790, 2005. 